\title{
CHALLENGES WHILE CARING FOR OLDER PEOPLE IN THEIR HOMES
}

\author{
Liga Rasnaca ${ }^{1}$, Dr.sc.soc., assoc.prof.; Endija Rezgale - Straidoma ${ }^{2}$, Mg.sc.soc. \\ ${ }_{1,2}$ University of Latvia
}

\begin{abstract}
In the start of the new millennium, the issues that are relating to ageing population draw attention of many policy makers as never before. The challenges that come with a rapidly aging population establish new relations between family, community and care organizations. The current study explores challenges in home care for older people in Oslo and Riga in comparative perspective. Authors explore what are the challenges in providing home care services for older people in Oslo and Riga. The study's research design is qualitative comparative case study. Results have been conducted from document and literature review on home care policy in Norway and Latvia, semi-structured interviews and express interviews. The main results show that in both cases proper social work is underestimated.
\end{abstract}

Key words: older people, carer, home care, risk.

JEL code: R1

\section{Introduction}

Researchers from various fields (gerontology, psychology, sociology, social policy, social work etc.) as well as policy makers draw attention to issues that are relating to an ageing population in the 21st century. In industrialized countries, people live longer and they have better health care than in the past (Green, Clarke, 2016). Rapid ageing demands for the social care services for older people. Policy makers have to come up with new alternatives on how to provide care for older people apart from institutionalized settings. The consequences of aging population affect the entire EU and EEA due to increasing life expectancy and consistently low levels of fertility over recent decades. The trend is expected to continue in the coming decades (EC, 2015). The challenges that come with a rapidly aging population establish new relations between family, community and caregiver organizations (Hollinrake, Thomas, 2015). The aim of the research is to find out challenges in home care for older people in Oslo and Riga applying comparative perspective. The relationship among stakeholders (caregiver organizations, municipalities, private companies etc.) and between carers, and care takers are of great importance.

Health and social care have not always been provided by professionals. Care mainly was provided by women within the family and the local community in the pre-industrial era. The development of knowledge-based occupation was a slow process, partly dependent on the development of vocational schools, and, for the medicine and the law, access to university based education. Different professional groups have a very different understanding, experiences and attitudes around participation in health and social care (Miers, 2010). The underestimated role of social work in home care relationships could be explained by historical development of professional home care as substitute of family functions in the past.

The social consequences of ageing and necessity for home care services are the topical issue in two cities: Oslo - capital of Norway, and Riga - capital of Latvia. The aim of the research is to find out challenges in home care for older people in Oslo and Riga in comparative perspective. The main research question is to find out what are the challenges in providing home care services for older people in these two cities? The tasks of the study are: 1) to construct theoretical framework for analyses of home care services for older people in the two cities; 2) to elaborate methodological framework; 3) to investigate relevant factors likely to explain differences between Oslo and Riga in home care for older people. Theoretical analysis is based on risk management, home care and quality assurances principles in home care for older people. 
Risk is considered to be a relatively new object of sociological research with rapid growth in research field in last decades (Lidskog, Sundqvist, 2013). Monica Barry, social work researcher from Stirling University defines risks in social work, paying attention on risks linked within organisational culture, inter-agency relationship and user collaboration (Barry, 2007, pp. 30-41). Authors are analysing challenges in home care according to the theory of risks by offering following risk structure. Risks are structured as risks linked with carers' and care takers' social position, and risks that could occur in relationships between both of them. The risk management approach is based on building barriers for possible hazards (for example, instructions, control etc.). The accurate and precise information about possible hazards and how to protect against them is best way in risk management (Adger, 2006, pp. 268-273). Authors are confident about necessity to focus on inter-agency relationships and user collaboration in home care case studies in Oslo and Riga.

Another parallel approach is vulnerability approach. The perspective of vulnerability could be defined as possibility to be harmed. It could be applied to aging society and home care for older people, too. If classical threats approach focus attention to external and internal threats/hazards, vulnerability approach is focused on more vulnerable elements and relations in home care, possibility to be harmed. Social care for older people is organized to support and protect vulnerable older people who need assistance. The carers also can be in vulnerable position due to overload at work, burnout and the way how care for older people is organized. Social care becomes vulnerable itself based on various patterns such as how care is managed and financed, and how society views it (Rossignoli, Fallon, Zwetkoff, 2014).

Home care is 'any type of care and support offered to older people in their homes, weather ordinary or specialised settings by formal and informal carers' (Tester, 1996). It is one of the alternative ways on how to provide help for older people towards the end of their life giving them an opportunity to stay out of long-term care institutions, letting them to live in their own home instead (Burau, Theobald, Blank, 2007). Home care is provided for older people or people with disabilities living in the community and they can receive services ranging from medical to non-medical (Newquist, DeLiema, Wilber, 2015). There could be involved representatives of various professional fields and organizations. It is a challenging task for all stakeholders to provide such a service that all parties are satisfied. Older people constitute the largest group who are using home care and these figures of them as home care service users will increase in the future. The reason for all countries to increase intensity in which they are addressing home care and engaging more actively in governing home care is the rapid ageing of their population (Burau et al., 2007). The main goal of home care services is to help older people to manage their own homes and to prevent them from premature institutionalization (Hagnelius, Wahlund, Schneede, Nilsson, 2012). Social work researchers emphasize importance for older people to receive emotional support, but it is difficult for carers in home care context to provide it since they often work under time pressure, leading to older people not receiving the emotional support that they require (Skilbeck, Payne, 2003). The coordination and cooperation between various caregivers and care takers is one of the most important issues and it is necessarily to pay attention in further empirical analysis.

Quality of home care could be characterized as topical issue for discussion among social workers, policy makers, health care representatives and other involved actors. Quality principles are the main moral responsibilities, guidelines for home care. Quality assurance strategies seek to prevent, detect, and correct problems in the quality of services provided to individuals and 
populations. Quality is multidimensional phenomena covering various aspects of research subject. Quality improvement strategies attempt to improve quality through continuous study and modification of the services being provided (Rezgale-Straidoma, Rasnaca, 2016; Adams, 1998, pp. 23-38). Authors choose to explore quality assurance principles elaborated by international team of researchers and described in the 'European strategy for wellbeing and dignity of older people (WeDO) in need of care and assistance' within the 'European Quality Framework for longterm care services' elaborated by social scientists from different countries in the context of EU Strategy 2020' (WeDO, 2012). The EU Strategy for the wellbeing and dignity of older people in need of care and assistance highlights 11 quality principles in long-term care services for older people. A quality service should be: respectful of human rights and dignity, person-centred, preventive and rehabilitative, available, accessible, affordable, comprehensive, continuous, outcome-oriented and evidence-based, transparent, gender and culture sensitive (WeDO, 2012). Main principles included the main points how the caregiving process and interaction between carers and care takers have to be organized. The implementations of quality assurance principles are threatened by risks in home care.

\section{Data and methods}

The research design is comparative case study. Home care for older people in Oslo and Riga for the analysis where chosen for several reasons: both are capitals having similar demographic characteristics, territorial distribution, and high percentage of an aging population. The economic situation as well as the amount and the variety of available resources to deal with social issues differ in great degree.

Data were obtained from extending previous knowledge of policies and organizational settings in home care for older people and how Norwegian and Latvian social welfare policy is implemented in both capitals. Additional data was collected through semi-structured and express interviews. Semistructured interviews were done with social carers, managers of home care services, social workers and older people. Express interviews were done with relatives of older people. The variety of research participants (Table 1.) in both cases can be explained with sensitivity of this topic. Ten semi-structured and nine express interviews were held between April and June 2016 in Oslo. Seven semi-structured and five express interviews were conducted in July and August 2016 in Riga. The eleven quality principles adopted from WeDO project were used as the basis of semi-structured interviews and additional questions were asked about risks in home care for older people.

Characteristics of the case studies

\begin{tabular}{|l|l|l|l|}
\hline \multicolumn{1}{|c|}{ Case } & \multicolumn{1}{|c|}{$\begin{array}{c}\text { Focus of the } \\
\text { study }\end{array}$} & \multicolumn{1}{|c|}{ Participants of the study } \\
$\begin{array}{l}\text { Case study } \\
\text { I (Oslo) }\end{array}$ & $\begin{array}{l}\text { Exploration of the } \\
\text { perception of } \\
\text { participants } \\
\text { concern }\end{array}$ & $\begin{array}{l}\text { Manager of social services (private company) } \\
\text { Social worker team leader } \\
\text { Carers } \\
\text { Oare takers } \\
\text { Relatives of care takers }\end{array}$ & $\begin{array}{l}\text { Home care } \\
\text { organization and } \\
\text { process for older } \\
\text { people in Oslo }\end{array}$ \\
\hline $\begin{array}{l}\text { Case study } \\
\text { II (Riga) }\end{array}$ & $\begin{array}{l}\text { Exploration of the } \\
\text { perception of } \\
\text { participants } \\
\text { concern }\end{array}$ & $\begin{array}{l}\text { Manager of social services (municipality) } \\
\text { Social worker- team leader } \\
\text { Carers } \\
\text { Care takers } \\
\text { Relatives of care takers }\end{array}$ & $\begin{array}{l}\text { Home care } \\
\text { organization and } \\
\text { process for older } \\
\text { people in Riga }\end{array}$ \\
\hline
\end{tabular}

Home care challenges for data analysis were grouped in six categories:1) profiles of carers and their working conditions; 2) health and wellbeing of older people;3) gender and cultural aspects in 
providing home care services; 4) organization of home care services; 5) social work considered in home care services; 6) vulnerability of carers and care takers. Data was analysed from risk and quality principle perspective. The study was carried out in accordance with the ethical requirements of consent, voluntariness, and confidentiality.

\section{Research results and discussion Home care in Oslo}

Norway health care system is based on equal access to all citizens irrespective of their social status, income and location' (Alzheimer Europe, 2009b). An average old age pension in Norway is 7715 NOK (831.58 EUR). According to Norwegian Labour and Welfare Administration from 1st of September 2016, the basic pension for married and cohabiting pensioners is 90 percent of the basic amount (NAV, 2016). 'The minimum pension level is a guaranteed minimum retirement pension payment from the National Insurance Scheme. With effect from 1 January 2011, the minimum pension level replaced the concept of basic pension for old age pensioners. This also applies to those who drew retirement pension before 2011 (for those who born 1954-1962), the minimum pension level will gradually be replaced with the term guarantee pension)' (NAV, 2015). The financial situation of older people is closely linked with possibilities to receive additional services, partly financed by municipalities. Home care is provided by private and municipal care givers.

\section{Home care in Riga}

In Latvia, average pension is less than 300 EUR. The minimal pensions are 70-109 EUR. The retirement age was 63 years in 2017. The retirement age will be increased up to 65 by 2025 . According to CSB (Central Statistical Bureau, 2015) reports, the average old age pension in Latvia was EUR 270. The majority (60\%) of pensioners receive pensions below the average (SSIA, 2016; CSB, 2015). There is a rising demand for care in people's homes and many municipalities in Latvia (Rezgale-Straidoma, Rasnaca, 2015). The need for home care services every year is increasing by ten percent (Davidavicus, 2014). The range of social services significantly differs across municipalities, and Riga citizens had better access of home care. If an old age person needs home care services and receives pension below 380 EUR, then home care is financed by municipality. Home care could be provided by municipal, private, or non-governmental organizations. The service providers could be accessible without assistance of municipal Social Service if income level is higher than average.

The home care services for older people have been provided in both cases. The differences between two cases are in financial principles and coverage of home care services for older people. The similarities of provision of home care services for older people in Oslo and Riga are involvement of both public and private organizations.

\section{Analysis of challenges in home care organization and process in both cases 1. Profile of carers and their working conditions}

Most of the carers don't have an education in social work and social care. The lack of skills, training and instructions, as well as satisfactory educational background is one of the factors affecting work of carer. Staff members involved in social care for older people receive only three days of training provided by the employer. The deficiencies in education and skills can lead to health problems. All interviewed carers admitted that they would need more time to learn how to care for older people. The common injuries that were mentioned by carers were spinal, hip and 
shoulder injuries. Another issue is a lack of time for each visit. As result to shortage of time carers have those injuries mentioned above.

Some of the carers are already used to stress and accepting it as a trait of their profession. In both cases, carers are doing the low paid work and some of them are ashamed of their job position, because this occupation is not considered as very prestigious in both cases. The daily schedule of carers is very tight, thus it is hard for them to make on time for the next appointment for seeing a next care taker. From the carers' perspective, more flaws are on how they are being treated in setting of home care services by both care taker and service management. The fact that in both cases home care services don't provide their staff with necessary training makes them to be at the risk of vulnerability.

Carers' work conditions including tight work schedule (time limits for each manipulation) and lack of professional skills and training are the risks for them working in home care services for older people. Older people and carers believed that hiring more staff would improve their ability to control their days.

\section{Health and wellbeing of older people}

The similar challenge in health and wellbeing of older people is lack of human factor in providing home care services such as communication and personal approach. Older people would like to receive more emotional support. It is difficult for carers in home care context to provide it since that requires an interpersonal interaction and communication, which is time consuming. In both cases, adults' children still have to look after their older parents. Those older persons whose relatives cannot actively take part and control process of home care services are at higher risk than those whose relatives or adult children are living nearby and communicating with their older people daily.

The difference is that in Oslo every older person gets very frustrated about the fact that each time they receive help from different carers, but in Riga home care service is organized quite opposite that every time the same carer is taking care of an older person.

The lack of interaction with other people puts older people under risk to suffer from boredom, frustration and isolation. The risks in home care for older person as care taker are unsatisfied emotional needs and lack of person - centred approach.

\section{Gender and cultural aspects in providing home care services}

The culture and gender sensitivity is one of the quality principles of the WeDO project. Care takers in Oslo home care services are older people who are both ethnical Norwegians and people with foreign ethnical background. In Riga, it is similar, but less ethnical diversity is represented. Gender bias was mentioned by carers as well, with some of them saying that they are unsure how to address this important issue with older people as care takers. Team leaders in both cases mentioned a right to dignity and respect as important to quality of life, and some older people do not want carer of opposite gender to help them with their daily routine. Even though ethnical diversity in both cases is different, the challenge concerning gender and culture in both cases are similar. Home care service managers must consider wishes of care takers in respect to one of the quality principles in care for older people (gender and culture sensitive) when it comes to choosing a carer for them. It is not always possible to meet demands of care takers. 


\section{Organization of home care services}

The impact of state government policy in both cities is supported by municipalities' efforts on keeping older people as long as possible in their homes by providing them necessary home services. Social care requires high costs, and governments have been highly criticized that they are not giving enough finances aimed at home care for older people in Oslo and Riga. There are not enough social carers in home care services, but governments are not providing enough finance in order to be able to afford to hire more workers. The main task for municipality, private home care services or NGOs is to provide home care by meeting basic needs for care takers. Carers complained that daily to do list is impossible to manage in order to get on time to the next care taker.

Another challenge in both cases in home care is that one has to go through very long bureaucratic process and has to be on a long waiting list in order to get not only additional helping aid devices but also to apply for home care services. In both cities, older people are in need for a consultation and advocacy from their relatives or close friends when they are choosing home care services. Home care in Oslo is divided in three positions: home assistant, carer and medical nurse. In Riga, medical nurse is not a part of home care system and it is separate service from social care and must be prescribed by general practitioner. Some medical manipulations in Riga home care carers are doing by themselves without medical education, for example, giving medication and measuring blood pressure to older person.

The rotation of carers takes place in Oslo but in Riga the tendency is quite opposite - carers are same persons all the time with the same care taker. In Oslo, main part of carers is immigrants; in Riga, carers mainly are people from rural areas. The risks for both care takers and carers are related to the way home services are organized by their management.

\section{Social work considered in home care services}

In both cases, supervisors have higher education but not in all cases it is in social work. There are so many home care clients and carers for head of departments or team leaders it becomes impossible to supervise carers' work properly. Work organization slightly differs from private company and municipality home care services. There is competition among private companies and municipality home care services. Carers feel undervalued for doing their work both in Norwegian and Latvian society. Relatives of care takers point out careless attitude of carers and some of them have changed service providers several times. Not always 'private' means a better service. There is a risk for older people to become the victims of crime due to the fact that every day an older person receives help from different carers.

\section{Vulnerability of carers and care takers}

Vulnerability refers to both carers and care takers. Carers are in stress due to social statuses that do not provide sufficient social protection; and the prestige of their profession is low in society. They are not protected from emotional offences from care takers and their employers. The work schedule determined by employers and team leaders put carers under additional pressure thus increasing an emotional strain. Adaptive capacity of social care not always could accommodate stress of social cares and protect care takers. Social care and medical care are separated. It is necessary for authorities in social and medical care to achieve an integrated approach and actions in care provision. 


\section{Conclusions}

1) Lack of an appropriate education, training and skills in social care leads carers to experience stress, burnout and injuries. It exposes carers to the risk of vulnerability.

2) Lack of appropriate professional organizations is an important factor that describes carers' vulnerable position.

3) Home care service providers are lacking individual approach and some demands of older people could lead to discrimination (carers should be of the same sex, religion or ethnical background).

4) Home care for older people causes vulnerable position in both cases. On the one hand, frequent rotation of carers for each client exposes home care to organizational risks in Oslo. On the hand, the fact that in Riga rotation of carers is not as frequent as in Oslo also leads to different organizational risks.

5) The major challenge is how to overcome consequences caused by cuts in public funding for home care in both countries. The lack of qualified staff and the time management problems endanger service quality in older persons' home care.

6) Considering social work, in both cases there are addressed several similar challenges such as how to prevent risk of older people from being lonely and becoming victims of crime, how to make older people feel more needed, and how to make social work more effective.

7) It is very important to be sensitive to the culture and gender issues when providing home care services in both cases.

\section{Acknowledgement}

This research has been generously supported by the project "PUBLIC HEALTH, QUALITY OF LIFE AND SUSTAINABLE DEVELOPMENT OF NATION".

\section{Bibliography}

1. Adams, R. (1998). Approaches to Quality Assurance in Social Work. Palgrave Macmillan, London.

2. Adger, N. W. (2006). Vulnerability. In: Global Environmental Change 16. pp. 268-281. Retrieved: http://www.geos.ed.ac.uk/ nabo/meetings/glthec/materials/simpson/GEC_sdarticle2.pdf

3. Alzheimer Europe (2009a). Latvia. Social Support Systems. Retrieved: http://www.alzheimereurope.org/Policy-in-Practice2/Country-comparisons/Social-support-systems/Latvia

4. Alzheimer Europe (2009b). Norway. Home Care. Retrieved: http://www.alzheimer-europe.org/Policy-inPractice2/Country-comparisons/Home-care/Norway

5. Barry, M. (2007). Effective Approaches to Risk Assessment in Social Work: An International Literature Review. Scottish Executive. Stirling University, Edinburgh. Retrieved: http://www.gov.scot/resource/doc/194419/0052192.pdf.

6. Burau, V., Theobald, H., Blank, R. H. (2007). Governing Home Care. A Cross-National Comparison. Globalization and Welfare. Edward Elgar. Cheltenham, UK; Northampton. MA USA. p. 224.

7. CSB (Central Statistical Bureau of Latvia) (2016). Resident population (demography). Retrieved: http://www.csb.gov.Iv/en/statistikas-temas/termini/resident-population-demography-35322.html

8. CSB (Central Statistical Bureau of Latvia) (2015). Sociala drosiba. Galvenie raditaji (Social Security. Key Indicators). Retrieved: http://www.csb.gov.Iv/statistikas-temas/sociala-drosiba-galvenie-raditaji30402.html.

9. Davidavicus, L. (2014). Aprupe majas: trukst darbinieku un kontroles - cies klienti (Home care: lack of control and employees - suffering clients). Retrieved: http://www.Ism.Iv/lv/raksts/zinjuanaliize/zinas/aprupe-majas-truks-darbinieku-un-kontroles--ciesh-klienti.a89217/

10. EC (2015). Demography Report. Short Analytical Web Note 3/2015. Employment, Social Affairs \& Inclusion. Eurostat. Retrieved from http://ec.europa.eu/eurostat/documents/3217494/6917833/KE-BM-15-003-ENN.pdf/76dac490-9176-47bc-80d9-029e1d967af6.

11. Green, L., Clarke, K. (2016). Social Policy for Social Work, Cambridge: Policy Press. p. 240.

12. Hagnelius, N., Wahlund, L., Schneede, J., Nilsson, T., K. (2012.) Blood Concentrations of Homocysteine and Methylmalonic Acid among Demented and Non-Demented Swedish Elderly with and without Home Care Services and Vitamin B12 Prescriptions. Dement Geriatr Cogn Dis Extra. 2012 Jan-Dec; 2(1) pp. 387-399. Retrieved: www.karger.com/dee Dementia Geriatric Cognitive Disorders Extra. 
13. Hollinrake, S., Thomas, W. (2015). Caring Relationships and Efficient Social Care Provision: Can an Ethic of Care Provide a Better Foundation for Responding to Care Needs in Later Life? International Journal of Sociology and Social Policy, Vol. 35 Issue: 5/6, pp. $419-436$.

14. Lidskog, R., Sundqvist, G. (2013). Sociology of Risk. Ch4. (Eds.) Roeser S., Hillerbrand R., Sandin P., Peterson M. Essentials of Risk Theory. Springer Briefs in Philosophy. Springer Dordrecht Heidelberg: New York, London.

15. Miers, M. (2010). Learning for New Ways of Working. Ch. 6. Understanding Interpersonal Working in Health Care and Social Care. Theory and Practice. (Eds.) Pollard, K., C., Thomas, J., Miers., M. Palgrave Macmillan, London. pp. 74-89.

16. NAV (Norwegian Labour and Welfare Administration) (2015). Minimum Pension Level (previously called a basic pension) Retrieved:

https://www.nav.no/en/Home/Benefits+and+services/Relatert+informasjon/minimum-pension-levelpreviously-called-a-basic-pension

17. NAV (Norwegian Labour and Welfare Administration) (2016). Vedlegg. Retrieved: https://www.nav.no/rettskildene/Vedlegg/vedlegg-6-til-kap.3-folketrygdens-grunnpensjon-ogs \%C3 \%A6rtillegg;cmsnavno_JSESSIONID=B0tIAerD-Y2FeMG1ROwuQELy

18. Newquist, D., DeLiema, M., Wilber, K. H. (2015). Beware of Data Gaps in Home Care Research: The Streetlight Effect and its Implications for Policy Making on Long-term Services and Supports. Medical Care Research and Review, 72(5), pp. 622-640.

19. OECD (The Organisation for Economic Co-operation and Development) (2015). OECD Economic Surveys Latvia. Retrieved: https://www.oecd.org/eco/surveys/Overview_Latvia_2015_Eng.pdf

20. OECD (The Organisation for Economic Co-operation and Development) (2016). OECD Economic Surveys Norway. Retrieved: http://www.oecd.org/eco/surveys/Norway-2016-overview.pdf

21. Rezgale-Straidoma, E., Rasnaca, L. (2015). Risks While Deinstitutionalizing Long-Term Elderly Care: The Case of Latvia. Socialiniai Tyrimai/Social Research, Siauliai University.

22. Rezgale-Straidoma, E., Rasnaca, L. (2016). Long-Term Elderly Care: Quality Assurance Challenges for Local Governments. Research for Rural Development, 2016 (2), LUA, Jelgava. pp. 203-209.

23. Rossignol, N., Fallon, C., Zwetkoff, C. (2014). "How Are You Vulnerable": Using Participation for Vulnerability Analysis in Emergency Planning. Journal of Risk Research, Routledge, pp. 1-20.

24.Skilbeck, J., Payne, S. (2003). Emotional Support and the Role of Clinical Nurse Specialists in Palliative Care. Journal of Advanced Nursing, 43, 521530. Retrieved: http://onlinelibrary.wiley.com/doi/10.1046/j.1365-2648.2003.02749.x/epdf

25. Tester, S. (1996). Community Care for Older People: A Comparative Perspective, Basingstoke: Macmillan.

26. WeDO (For the Wellbeing and Dignity of Older people) (2012). European Quality Framework for Long-term Care Services. WeDO project 2010-2012. Retrieved: http://www.wedo-partnership.eu/european-qualityframework-long-term-care-services 